\title{
CHROMATE DERMATITIS FROM PAINT
}

\author{
BY \\ H. O. ENGEL and C. D. CALNAN \\ From the Ford Motor Company Ltd., Dagenham, Essex and The Institute of Dermatology, \\ St. John's Hospital for Diseases of the Skin, Leicester Square, London, W.C.2
}

(RECEIVED FOR PUBLICATION SEPTEMBER 29, 1962)

\begin{abstract}
Among 250 workers engaged on wet sandpapering of primer paint on car bodies 65 developed a contact dermatitis. The average latent period before dermatitis developed was 4.6 months: only $60 \%$ of the patients made a completely satisfactory recovery. The average duration of dermatitis was $5 \cdot 3$ months.

Two thirds of the men used one of two barrier creams supplied, while one third used none. Routine patch testing showed that the majority was allergic to chromate. It was found that a primer paint contained zinc chromate, which had been introduced into the paint by the manufacturers shortly before the first cases occurred. Removal of chromate from the paint resulted in a prompt cessation of new cases of dermatitis.
\end{abstract}

An outbreak of dermatitis recently occurred in a motor-car factory group among workers who rub down paintwork on car bodies with sandpaper under wet conditions. It eventually affected 65 men out of a total of 250 at risk. The outbreak occurred in two nearby, but quite separate, factories (a new and an old factory) which had different water supplies. The cause was traced to a paint, though not without some difficulty, and was successfully eliminated. The personnel affected have been followed up for more than one year. The paint responsible for the trouble was used in other motor-car factories, where it had caused similar outbreaks of dermatitis. Several interesting and instructive points were noted during the study.

\section{The Process}

The motor-car bodies are sprayed by hand with a quick drying red oxide primer paint (surfacer), followed by a grey surfacer, after which the paint is baked in ovens at $310^{\circ} \mathrm{F}$. $\left(155^{\circ} \mathrm{C}\right.$.) for 30 minutes. The car bodies then travel down a line where the baked primer paints are rubbed down with silicon carbide papers, popularly known as sandpapers, under a flood of water in preparation for the final enamel paint spraying. This area is known as the "wet-deck". Sandpapering is carried out by hand, dipping the sandpapers in water troughs, or by rotatory sanding machines under a spray of water. Any rough irregular areas are rubbed more deeply, often exposing and sanding the red oxide primer as well (Fig. 1). After a final water rinse the bodies are dried in an oven, and subsequently "dry sanding" with sandpapers is carried out where necessary by other operators in preparation for the final enamel paint coats. A few men may wet-sandpaper small areas with cans of de-ionized water. After spraying with enamel and baking, it may be necessary for parts of the enamel paint to be rubbed down by hand with dry and wet sandpapers before being resprayed. A new method of using clarified and re-circulated water was introduced into the new factory. The

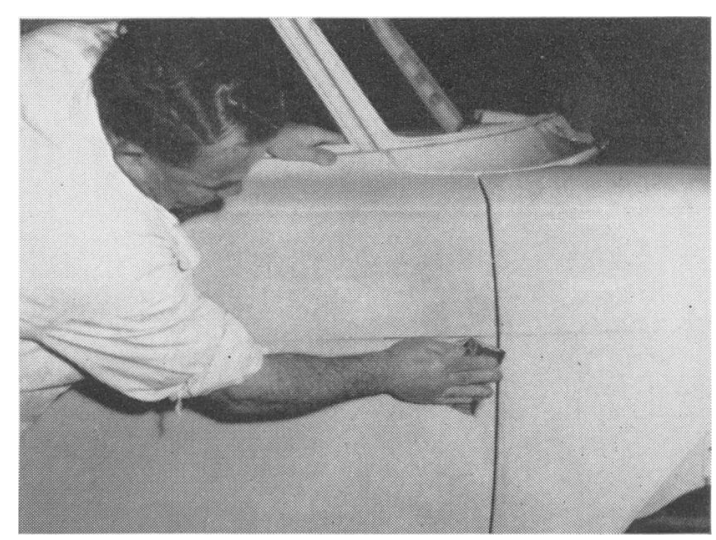

Fig. 1.-Wet sanding 
water from the troughs and sprays is drained into a large tank. It combines with the de-ionized water which is used as a final rinse. The water in the tank is treated with ferrous sulphate, chlorine, and caustic soda, which induces a flocculation of the abraded paint particles with the ferrous hydroxide produced. Sodium sulphate and sodium chloride form in the reaction and remain in solution. The excess chlorine is reduced to $0 \cdot 1$ part per million with sulphur dioxide. The water subsequently has a $p \mathrm{H}$ of about 8.0 and a dissolved solids content equivalent to about two thirds of that of ordinary town water.

\section{History of the Outbreak}

In November, 1959, one of us (H.O.E.) appreciated that an increasing number of men with skin complaints was attending the works surgery which served the new factory. These were all in a group of 60 engaged on the wet sand-papering (wet sanding) of the primer paint. Men carrying out the same job under dry conditions in the same department were quite unaffected, as were the enamel paint sanders. This new factory started wet sanding of paintwork in August, 1959. In addition to the newly engaged men, an increasing number of men were gradually transferred to this work from the older factory. Wet sanding continued in the older factory with its diminishing labour force, which was reduced to 30 by June, 1960. At that time 200 men were working in the new factory.

It was initially suspected that the cause of the dermatitis was to be found in the method of working, since a new type of circulating water supply, as described above, had been put into use. Although a few sporadic cases of dermatitis had occurred in the older factory, no significance was attached to them, it being assumed that they were cases of nonspecific irritant dermatitis associated with wet work. The closed water system was a new and complicated method of working, and some fault in the process of demineralization, clarification, or $p \mathrm{H}$ regulation was thought to be responsible.

When attention was turned to the particular primer paint applied, the use of triethylamine $(0.25 \%)$ as a stabilizer was suspected by the manufacturers of the paint, perhaps because it had been recently added and because they had been informed that another automobile company had encountered dermatitis from the same paint. On March 17, 1960, the stabilizer in the paint was changed to hydroquinone $(0.25 \%)$, but the incidence of dermatitis among the wet sanders did not diminish, as can be seen from Fig. 2. In May, 1960, chromate was suspected as being causative, following cutaneous patch tests on a sample of the men affected. On June 18 chromates were removed from the red oxide primer paint, and after that the outbreak rapidly subsided, although occasional sporadic cases have been seen subsequently (Fig. 2).

\section{Clinical Features}

The skin lesion was usually a red, scaly or vesicular dermatitis involving the fingers, hands, and forearms. The pattern varied in appearance; some showed only erythema or scattered papules, some showed areas of patchy eczema, and others resembled a dyshidrotic pompholyx type of eruption, nummular eczema, or a follicular irritative dermatitis. Some were red, dry, and scaly, whereas others were moist and exudative.

Pattern of Dermatitis.-As regards the distribution of the dermatosis, all the 65 patients had lesions on

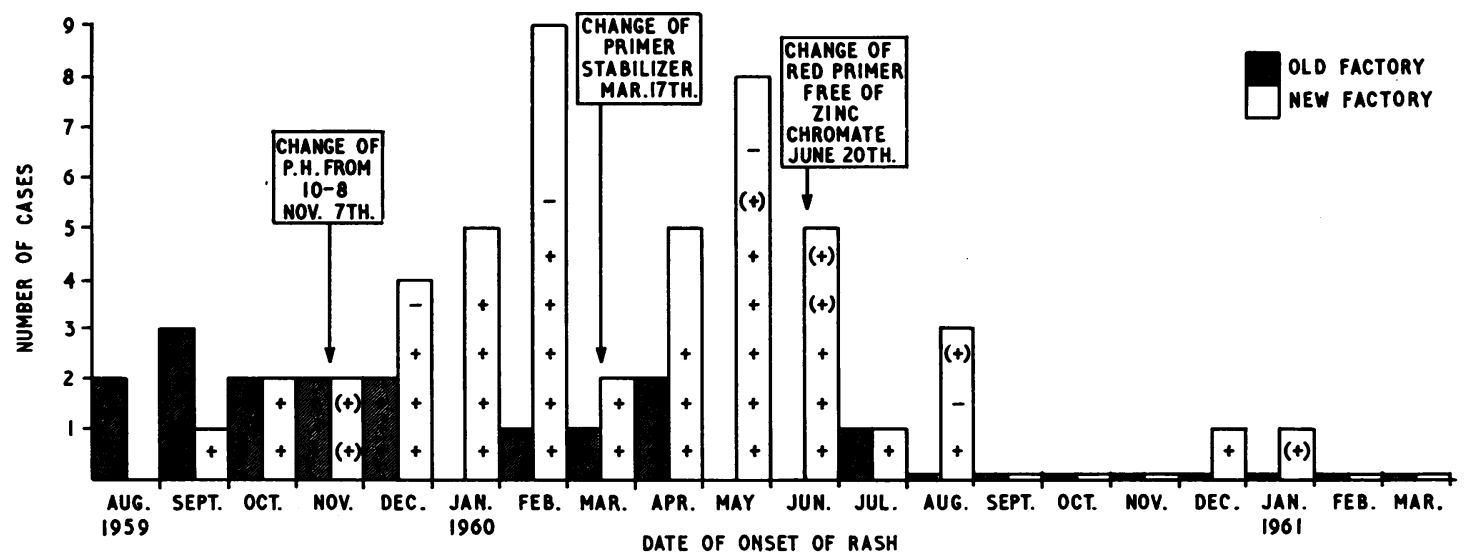

FIG. 2.-Incidence of cases of dermatitis from wet sanding process from August, 1959, to March, 1961. 
the hands ( 45 cases) and/or the forearms ( 36 cases), mostly symmetrical. (The men use both hands alternately when wet sanding.) In only two persons were the upper arms affected, in one the neck and face, and in another the trunk as well; all were chromate-positive. The eruption often varied its clinical appearance and distribution over weeks or months, and on many occasions it was virtually indistinguishable from atopic, nummular, or seborrhoeic eczema. Hall (1944) recorded similar observations in his patients with chromate dermatitis from paint, particularly remarking on the nummular pattern. The pattern of the dermatitis is also reminiscent of that found in cases of cement dermatitis associated with chromate sensitivity (Calnan, 1960). It appears that chromate sensitization has a special propensity to produce dermatitis simulating types of constitutional eczema. Unless one is aware of this hazard there is a considerable risk that genuine cases of occupational dermatitis will be misdiagnosed.

Severity.-The cases varied considerably in severity, but only four men lost time from work, their absence periods being from one to 10 weeks. It was the policy to keep the men at work on alternative dry work whilst receiving treatment at the medical centre. Treatment consisted of simple local applications including topical hydrocortisone. Systemic steroids were not given until after this investigation.

Previous and Family History.-A previous history of some cutaneous disorder was recorded in 17 of our 65 patients, not all of them being eczematous dermatoses. Only two patients gave a family history of eczema or dermatitis.

Age. - The average age of the affected men was 36 years. The average age of all the men at risk on the wet sanding operation was 34 years. The youngest affected patient was 20 , and the oldest 57 . Susceptibility to allergic contact sensitization is equal at all ages, although the opportunities and degree of exposure may vary throughout life. The age incidence of the dermatitis cases is therefore the same as that of the men at risk, as one would expect.

Latent Period.- - Hall (1944) believed that the latent period before chromate sensitivity and dermatitis, which was developed by his aircraft workers when exposed to zinc chromate, was a long one. It varied from one week to nine years with an average of seven months. In our patients this was very much shorter. The average duration of working time on wet sanding was 24.3 months, but the chromate hazard was not present until August, 1959. Our first cases appeared in August, 1959, and new cases continued to occur until January, 1961, which was seven months after chromate had been withdrawn from the paint. Some chromate may have continued to circulate in the closed water supply system, although it was emptied, cleaned out, and replenished in August, 1960. The average time of exposure to the hazard in our patients was 4.6 months, the range being from three days to 12 months. Recurrences on returning to the job after resolution of their dermatitis occurred within a few hours in several men.

Duration.-The course of the dermatitis in most patients was relatively protracted, and much longer than one would normally expect with a specific allergic contact sensitivity. The average duration was 5.3 months, but this excludes a small number of patients whose dermatitis has become chronic and persistent, as well as a few who have not been traced. Quite a number of the patients ran an intermittent course with relapses and remissions. At least eight men had relapses whilst employed on dry jobs away from any known exposure to chromate. Twelve men had recurrences after a return to the wet sanding work when the chromate had been removed from the paint primer. Such a recurrence occurred immediately in some men but not until a year later in others.

Chronicity and a tendency to relapse has been commented upon by others as a particular feature of chromate dermatitis (Samitz, 1955; Calnan, 1960). This is certainly very characteristic of cement dermatitis associated with chromate sensitivity, where alkalinity and trauma may be additional factors, but it is also frequent in instances of apparently uncomplicated chromate sensitization. No satisfactory explanation has been put forward to explain this chronicity, except for the observation that the presence of chromate is extremely widespread in the environment of some factories. Samitz (1956) was able to detect it on the towels, door handles, benches, tools, and many other sites in a printing works. Hence, it is often difficult to be certain that a worker does not continue to be exposed to chromate. For example, some metal components such as nuts and bolts may be treated with chromate as an anticorrosive. That this is not the entire explanation is shown by the fact that chromate dermatitis tends to remain chronic even if patients are put off work or are admitted to hospital.

Follow-up.-It was possible to find alternative employment for all the affected men. One man, a mild case, wished to continue at the same job, which he did successfully, his dermatitis resolving completely. Sixteen men later returned to wet sanding after the 
hazard had been removed and did not relapse. One year after the end of the outbreak as many men as possible were re-examined. It was found that $13 \mathrm{had}$ left to take up other employment; 31 were completely free from dermatitis; five had persistent chronic dermatitis; and 16 had mild occasional relapses. Hence the rate of complete recovery was only $60 \%$.

\section{Barrier Creams}

The affected patients were asked about their use of barrier creams. Two brands of proprietary creams were provided for the men on wet sanding. Their use is not compulsory, but the creams are provided and the men are encouraged to use them. Both of the creams were of a formulation recommended by the manufacturers for this type of work, although the manufacturers clearly could not be aware of the chromate dermatitis hazard. One man used a proprietary barrier cream of his own. The use of barrier creams by the 65 men with dermatitis was as follows:-

Brand A cream was used by 19 men, brand B by 23 men, and brand $C$ by one man. One man had used cream of brands A and B. No barrier cream was used by 21 of the 65 men. Hence, approximately one third of the men who subsequently developed dermatitis used one brand of cream, one third used a second brand, and one third used none. It is not known what proportion of the unaffected men used either of the two creams supplied or none at all, so that one cannot draw absolute conclusions about the relative values of such prophylactic means against the hazard. If, however, the proportion of users of the creams was the same in the unaffected men as in those with dermatitis, one could say that neither of the two barrier creams was effective in preventing dermatitis. The claims put forward for most barrier creams are in relation to primary irritant dermatitis, since virtually none of the creams available can completely prevent penetration. Only a small amount of a sensitizing chemical, such as the chromate ion, is required to produce a reaction in a specifically allergic person.

\section{Patch Tests}

A few patients were originally patch tested with the dried and baked red oxide primer paint and they were negative. They were also tested with the synthetic resins and the two stabilizers, triethylamine and hydroquinone, with equally negative results. None was tested with the fresh paints in either a wet or a dry state.

Six patients were tested with the standard series of patch-test materials shown in Table 1, and the only
TABLE 1

STANDARD SERIES OF PATCH-TESTING MATERIALS

\begin{tabular}{l|c}
\hline & $\%$ \\
\hline Colophony & 50 \\
Balsam of Peru & 25 \\
Salicylic acid & 5 \\
Sulphathiazole & $2 \cdot 5$ \\
Formalin & $3 \cdot 5$ \\
Mercuric chloride & 1 \\
Potassium dichromate & $0 \cdot 5$ \\
Silver nitrate & 2 \\
Nickel sulphate & 5 \\
Resorcin & 1 \\
Primula leaf & 100 \\
Pure coal tar & 1 \\
Quinine & $0 \cdot 5$ \\
Iodine & 2 \\
Paraphenylene diamine & 1 \\
Mercaptobenzothiazole & 1 \\
Tetramethylthiuramdisulphide & 5 \\
Turpentine & \\
\hline
\end{tabular}

positive reactions were to potassium dichromate in five of them.

Subsequently 58 of the 65 affected patients were tested with potassium dichromate. The results are shown in Table 2 . It can be seen that $91 \%$ of the patients tested were positive to dichromate. The other seven could not be tested for various reasons, such as change of work location and one refusal. Eight patients were negative to the routine aqueous solution of dichromate but gave a positive reaction

TABLE 2

PATCH TEST RESULTS WITH DICHROMATE 0.5\%

\begin{tabular}{c|c}
\hline Test Result & Number \\
\hline+ & $7(12 \%)$ \\
++ & $32(55 \%)$ \\
+++ & $14(24 \%)$ \\
$5(9 \%)$ \\
\hline Total & $58(100 \%)$ \\
\hline
\end{tabular}

when it was diluted in a buffer of $p \mathrm{H} 10 \cdot 3$. A similar effect of alkalinity has been reported by Spier and Natzel (1952) in some patients with cement dermatitis. The alkaline buffer much enhanced the weakly positive results of four patients.

\section{Incidence}

A total of some 250 male employees, including a number of coloured men, have been at risk on day and night shifts during the period reviewed. Some have transferred to other departments or left the firm for various reasons. This is quite a strenuous job, and the conditions are damp. Some men would normally obtain less active or drier work through non-medical agencies, but the turnover of personnel was small. The number of patients who reported to the medical department was 65 out of 250 at risk, or 
$26 \%$. It is thought that some minor eruptions or rashes of short duration may have escaped our notice because employees were aware that they might be put on dry work if they reported sick; this would probably result in the loss of overtime payments and loss of the satisfaction of a regular steady job in their own group. On the other hand, the problem was well recognized in the department. The shop-steward had a mild attack of dermatitis himself and consequently encouraged more marked cases to report for treatment.

Four men worked on the servicing of the water clarification tank. Three of them developed a contact dermatitis and were found to be sensitized to chromate, presumably from paint particles in the water.

\section{The Investigation}

The group of men involved in this outbreak of dermatitis was very uniform as regards their occupation. They were all engaged on virtually identical work and were doing only one job throughout. No gloves can be satisfactorily worn by men when they are wet sanding. They normally come into contact with only four materials, barrier cream, sandpapers, water, and paint sludge and grindings. Each of these materials was considered in turn.

Barrier cream was excluded on the ground that a number of the affected men had not used any cream at all. One cannot say whether it had any precipitating action in the pathogenesis of the dermatitis, but equally one can state that the use of barrier cream was not an effective prophylactic.

The type of silicon carbide papers in use had been unchanged for some years in the older factory, without dermatitis occurring, and they were not known to have been altered in composition since the opening of the new factory. Patch tests with the sandpapers and with the adhesive used in their manufacture were entirely negative in a random sample of affected men.

Some element in the water used was at first thought to be the cause of the trouble, mainly because the outbreak of dermatitis began soon after the opening of the new factory with its recirculating water plant, and also because the water system was the only known change in working conditions. The old factory used ordinary town water which was allowed to drain to waste. It was in order to conserve water that the recirculating water plant was installed when the second factory was opened. The water drains to a reservoir where it is clarified with flocculants and mixed with deionized water, so that fairly pure water is returned to the supply source for use by the wet sanders. The smaller number of men engaged on "dry sanding" were free of dermatitis and this evidence also focused attention on the water supply. It was possible that some residue from the paint sludge was accumulating in the water supply as a result of re-circulation, but no evidence was found to support such a view. The $p \mathrm{H}$ of the water supply was initially 10 . This was changed to $p \mathrm{H} 8$ from November, 1959, in order to reduce the alkalinity which might be a factor in facilitating dermatitis, but without any effect on its incidence (Fig. 2).

Enquiries were made about the composition of the primer paint from the manufacturers. This was suspected when cases of dermatitis appeared in the older factory, which did not have the recirculating water supply. Furthermore, it became known that similar trouble was being encountered by another car factory in men doing the same work with the same brand of paint. The paint was said to contain iron oxide, titanium dioxide, barytes, carbon black, alkyd and melamine formaldehyde resins, and triethylamine as a stabilizer (see Table 3). Patch tests to the resins

TABLE 3

COMPOSITION OF THE RED OXIDE AND GREY SURFACER PAINTS

\begin{tabular}{|c|c|}
\hline Grey Surfacer Paint & Red Oxide Paint \\
\hline $\begin{array}{l}\text { Bone black } \\
\text { Barytes } \\
\text { Calcium carbonate } \\
\text { Titanium dioxide } \\
\text { Alkyd resin } \\
\text { Melamine resin } \\
\text { Butyl alcohol } \\
\text { Aromatic hydrocarbons } \\
\text { Hydroquinone }\end{array}$ & $\begin{array}{l}\text { Natural iron oxide } \\
\text { Barytes } \\
\text { Calcium carbonate } \\
\text { Zinc chromate } \\
\text { Alkyd resin } \\
\text { Melamine resin } \\
\text { Butyl alcohol } \\
\text { Aromatic hydrocarbons } \\
\text { Hydroquinone }\end{array}$ \\
\hline \multicolumn{2}{|c|}{$\begin{array}{l}\text { Alkyd Resin Constituents } \\
\text { Linseed and soya bean oils and their acids } \\
\text { Glycerine } \\
\text { Phthalic anhydride } \\
\text { Rosin }\end{array}$} \\
\hline \multicolumn{2}{|c|}{$\begin{array}{l}\text { Melamine Resin Constituents } \\
\text { Melamine-formaldehyde } \\
\text { Butyl alcohol } \\
\text { Butyl formal } \\
\text { Methylol melamine } \\
\text { Butyl ethers of methylol melamine }\end{array}$} \\
\hline
\end{tabular}

were negative, as were tests with other fractions of the paint after it had been baked. As mentioned above, triethylamine was suspected as the cause by the paint manufacturers, although little if any of this compound would be likely to be still present in the dry baked paint film on the car bodies. Hydroquinone was substituted for triethylamine as a stabilizer in the paint without any improvement in the incidence of dermatitis. No positive patch tests were obtained with either substance.

At this stage six of the affected men were patch tested with a number of known constituents of the paint as well as with some of the substances in a standard patch test series (Table 1). The only 
positive results obtained were reactions to potassium dichromate $(0.5 \%)$ in five of the six men. This was regarded as very strong evidence that their dermatitis was attributable to chromate sensitivity. Hence, a search for possible sources of chromate was begun; the circulating water was tested but none was found. Direct inquiry to the paint manufacturers eventually revealed that the red oxide undercoat primer contained $2.25 \%$ of zinc chromate, which, after evaporation of the solvents and baking, rose to $6.3 \%$ in the dry surfacer. No chromate was present in the outer grey primer paint.

Subsequently all available men with dermatitis were patch tested with chromate. Positive reactions were found in 53 out of 58 men tested. Among 16 men affected in the older factory, 15 were tested and all except one were positive.

It then transpired that zinc chromate had only been introduced into the red oxide primer paint by the manufacturer in August, 1959. Although the paint had been used by the automobile factory for many years, no person in the factory knew of this change, and it appears likely that some representatives of the paint firm did not know of it either, at the time the first enquiries were made.

\section{Discussion}

During the past decade there has been a steadily increasing interest in dermatitis due to chromates, especially amongst dermatologists interested in occupational disease (Samitz, 1955). Furthermore, there is a widespread impression that the incidence of chromate dermatitis is rising, although there are few accurate statistics to prove this. Two recently published studies provide some evidence of a rising incidence. In the first, Marcussen (1962) has analysed the results of the so-called standard patch test series on all patients with eczema or dermatitis (we use

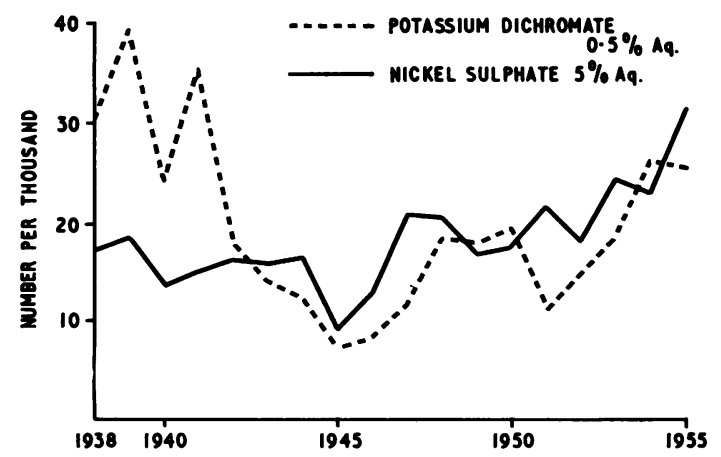

FIG. 3.-Incidence of positive patch tests to chromate at the Finsen 3 these terms synonymously) attending the Department of Dermatology at the Finsen Institute in Copenhagen from 1935 to 1959 . Every dermatitis patient was tested with 24 substances including potassium dichromate $0.5 \%$ in water. The number of patients tested showed some year-to-year fluctuations but the overall percentage giving a positive reaction to one or more substances was remarkably constant at around $30 \%$. However, the percentage of reactors to individual substances has changed considerably over the years, and the proportion of reactors to chromate is steadily increasing (Fig. 3). In the second study Wagner (1959), at the Dermatological Clinic in Kiel, analysed the results of 500 patients who had been diagnosed as cases of allergic contact dermatitis and patch tested with a similar series of standard test substances. Potassium dichromate gave the highest percentage of reactions amongst men with a figure of $33.6 \%$. Experience in Switzerland is similar. The most frequent cause of this chromate sensitivity is undoubtedly cement dermatitis, although it does not account for all the cases. Chrome salts are widely used in many industrial processes (apart from their incidental presence in cement products) such as printing and engraving, photography, dyeing, electroplating, and leather manufacture. Only recently one of us (H.O.E.) established at this factory that many cases of presumed "oil dermatitis" are actually attributable to an anticorrosive bichromate rinse of the nuts and bolts used in assembly work (Newhouse, 1963).

Chromates and dichromates are used in paints, sometimes as colouring agents, but more frequently as anti-rust or anti-corrosive agents, and are therefore usually used in primer paints. Hall (1944) published a study of skin disorders in a large aircraft factory in Southern California over a period of seven months. In this factory employing 45,000 workers he saw 755 patients referred to him as suspected cases of industrial dermatitis. In the analysis he excluded 175 cases because of inadequate information. Of the remaining 580 , he regarded $210(36.2 \%)$ as having non-industrial skin disorders and $202(34.8 \%)$ as having acceptable occupational dermatitis. The biggest single cause of dermatitis was a primer paint containing zinc chromate; this was responsible for 132 cases, or $65.2 \%$ of all the industrial cases. Not all the cases were due to the chromate, since patch testing revealed that $68 \%$ were sensitized to chromate, $17 \%$ to one or more resins, and $15 \%$ were sensitive to both chromate and resins.

The outbreak in an automobile factory described in this paper is remarkably similar to Hall's (1944) experience in relation to the chromatic sensitization and to the clinical features. Hall's patients, however, were exposed during the actual application of a zinc 
chromate primer paint. We have not encountered a single case of dermatitis among the men who were applying the primer paint, a fact which originally tended to divert attention from the paint itself as a suspected cause. However, the men who applied the paint in spray booths were well insulated by protective clothing, except over their faces. They smeared their faces with soft paraffin before work to protect their skin and to facilitate cleansing; this procedure almost certainly protected the only exposed site.

The three most important points which have come out of this study are, in our view, the usefulness of routine or standard patch testing, the failure of barrier creams to prevent a sensitization dermatitis, and the effective means of prevention. In one other car factory which experienced the same problem from using the identical chromate primer paint, no skin tests were performed and the particular paint could only be incriminated because it was used on one assembly line only. Two other assembly lines had no trouble when carrying out the same wet sanding process on car bodies treated with primer paint from other manufacturers. It was not possible to go further than conclude that the cause of the trouble lay in the paint, and hence no advice could be given to the paint manufacturer. With standard patch testing, on the other hand, we had good evidence that chromate was the cause of the outbreak, in spite of being misinformed that the primer paint contained no chromate when we enquired about its constituents. If the first cases had been subjected to routine patch tests it is likely that chromate would have been incriminated at an earlier stage and its source traced to the primer paint. Routine patch testing is especially indicated in instances of possible chromate sensitivity because of its propensity to mimic constitutional patterns of eczema and primary irritant dermatitis. It does not often present as an acute vesicular, exudative, and oedematous dermatitis. In cases of cement dermatitis most observers find it extremely difficult to prophesy with any confidence whether chromate sensitivity is present or not.
The failure of two standard brands of industrial barrier creams to prevent dermatitis in the men who used them is striking. A great deal of controversy surrounds the use of barrier creams in industry. Many industrial medical officers feel that it is likely to be extremely difficult or impossible to set up a properly controlled investigation in a factory on a large enough scale to obtain significant results. In the present case, although the numbers are small, it seems justifiable to conclude that the use of neither of the two proprietary creams was of prophylactic value.

Once the cause was traced and removed, the outbreak of dermatitis rapidly came to an end. No other measure could be more effective, and it is clearly the best method when feasible. The primer paint concerned is said to be as effective without the chromate. If this is so, one wonders why it was ever incorporated in the paint! It is likely that most paint manufacturers are unaware of the dermatitic hazards. In many instances appropriate research by manufacturers can find alternative materials, and should always be the first method advocated in the prevention of industrial dermatitis. The primer paint at present in use contains a small amount of epoxy resin and is considered to be as effective as a protective base coat for the metal.

We should like to thank Dr. M. Newhouse and chemists of Ford Motor Company for their assistance, and we are particularly indebted to the employees and their representatives, whose co-operation made this investigation possible. We also thank the management of Ford Motor Company and Dr. J. N. Macdonald for permission to publish this article.

\section{REFERENCES}

Calnan, C. D. (1960). J. occup. Med., 2, 15.

Hall, A. F. (1944). J. Amer. med. Ass., 125, 179.

Marcussen, P. (1962). Trans. St. John's Hosp. derm. Soc. (Lond.), 48, 1 Mewhouse, M. (1963). Brit. J. industr. Med., 20, 199.

Samitz, M. H. (1955). A.M.A. Arch. industr. Hlth, 11, 361.

Samitz, M. H. (1955). A.M.

Spier, H.W., and Natzel, R. (1952). Arch. Derm. Syph. (Berl.), 193, 537

Wagner, G. (1959). Berufsdermatosen, 7, 307. 